\title{
Arteterapia como acompañamiento para la construcción y empoderamiento de la subjetividad femenina
}

\author{
Araceli GUIOTE GONZÁLEZ \\ Facultad de Ciencias de la Educación y Bellas Artes de la Universidad de Granada. \\ aguiote@hotmail.com
}

Recibido: 20.10 .2013

Aceptado: 15.11 .2013

\begin{abstract}
RESUMEN
Los estudios de subjetividad femenina plantean que la mujer es susceptible de sufrir trastornos psicosomáticos y estados de enfermedad como consecuencia de un modo de sociabilización "normalizado" (valores, creencias, asunciones...), que impide la construcción de los deseos propios y una inhibición del yo, dando lugar a "estados de subjetividad subordinados". En este espacio se va a exponer por un lado, la aplicación del arteterapia para el tratamiento de mujeres que sufren el síndrome de fibromialgia. Por otro lado, se va a invitar al lector a reflexionar sobre la relación entre acontecimientos traumáticos en la novela familiar del sujeto, la incorporación de los valores dominantes sobre la mujer y el malestar psíquico a través de la expresión creativa. Mediante el recorrido ilustrativo de la producción artística de un estudio de caso, se va a mostrar el arteterpia desde la multifuncionalidad por la que se puede caracterizar, siendo algunas de ellas: la posibilidad del arteterapia como acompañamiento para la creación y la transformación de conflictos emocionales, y la construcción y empoderamiento de la subjetividad femenina. Este estudio forma parte de un proceso doctoral con mención internacional, actualmente financiado por el consorcio para investigadores de la Unión Europea, proyecto EDEN y entre las universidades participantes se encuentran: Granada, Madrid, Londres, e Israet.
\end{abstract}

Palabras clave: Mandatos de género, dolor, arteterapia, subjetividad femenina, empoderamiento.

\begin{abstract}
Studies dedicated to female subjectivity show that women are susceptible to suffer psychosomatic disturbances and states of disease, as a result of a "standard" mode of socialization (values, beliefs, assumptions...) which prevents the construction of own desires and an inhibition of the self, giving rise to "subordinate States of subjectivity". This article will expose, on the one hand, the application of art as a therapy for the treatment of women suffering from fibromyalgia syndrome. On the other hand, it will invite the reader to reflect on the relationship between traumatic chronology in the family saga of the subject, the incorporation of dominant values on women and the psychic discomfort through creative expression. Through the illustrative material of the artistic production of a case study, it will show art from the multifunctionality that can be characterized, being some of them: the possibility of art as an accompaniment for the creation and transformation of emotional conflicts and the building and empowerment of female subjectivity. This study is part of a doctoral process with international mention, currently funded by the Consortium for researchers in the European Union, the EDEN project. The participating universities are: Granada, Madrid, London, and Israel.
\end{abstract}

Key words: Mandates of gender, female subjectivity, art therapy, pain, and empowerment. 


\section{INTRODUCCIÓN}

Los informes, estudios y encuestas sobre salud vienen mostrando que las mujeres tienen peor salud física, mental y padecen trastornos psicoactivos en mayor medida que los varones (Observatorio de Salud de las Mujeres, 2004-2007). Los factores que explican esta situación son muchos y de diversa naturaleza, incluyendo factores de tipo biológico, psicológico o social (Lasheras, Pires y Rodríguez, 2004). Tradicionalmente, estos factores han sido analizados desde una supuesta neutralidad que ha dado origen a importantes sesgos androcéntricos (Sen, George, Ostlin, 2005). El punto de vista feminista ha aportado, en este sentido, un análisis integrador que, no sólo incorpora el género como determinante de la salud, si no que cuestiona el orden social patriarcal que, en última instancia, explicaría las desigualdades subyacentes.

A lo largo de la historia, el sometimiento de las mujeres al sistema patriarcal es uno más entre los múltiples sometimientos que ocurren y que generan patologías dentro del sistema. Pero en este espacio me gustaría mencionar dos esferas importantes a lo que la mujer fue vetada: el acceso a su mundo interior y el acceso al mundo del arte. Desde el rol que le fue asignado a la mujer procedente de la mirada patriarcal, hallamos en los estudios subjetivos de la feminidad características de los mandatos de género como: pasividad, inmanencia, ser buenas, centrarse en los hijos, la pareja, construcción identitaria como persona y mujer en relación a los vínculos afectivos, el mantenimiento de las relaciones amorosas, en espera, renuncia. Es especialmente "alarmante" como dichas características no solo afectan a la configuración de una identidad social, económica, político, etc...sino que construyen, mediante la heteroasignación ${ }^{1}$ de la mirada masculina, un cuerpo de identidad femenino (que anula la diversidad de la mujer), como un espejo, donde proyección y reflejo viene a ser una misma cara de la realidad. Jeammet exponía que la agresividad es el esfuerzo del ser humano por afirmarse, por defender su territorio psíquico o del yo. Sobre esto (López, 2013) ${ }^{2}$ cita:

“...La agresividad de las mujeres ha sido moldeada por el patriarcado mediante una educación que emparentaba cualquiera de sus manifestaciones con lo monstruoso y lo feo, lo inaceptable. Ha sido podada en todas sus ramas desde que somos niñas, y la mujer bonsai resultante de esta poda sistemática no tiene más remedio que ejercerla contra sí misma, manifestándose en trastornos psicosomáticos, obesidad o ansiedad

\footnotetext{
${ }^{1}$ Simone de Beauvoir (2008) afirmó que «La Mujer » es una heterodesignación, un objeto de discurso por parte de los varones que la instituyen en "la Otra", relegándola así a la esfera de la alteridad, la inesencialidad y la inmanencia.

${ }^{2}$ Citado por Lola López Modéjar (2013) en Histeria, Literatura y psicoanálisis: Ana Karenina, Ana Ozores y Emma Bovary, en una conferencia presentada en el curso de Arteterapia, en la Univ. de Granada.
} 
generalizada. Es lo que le sucede, también, a la mujer víctima de la violencia doméstica".

Actualmente, cuando encontramos en la clínica tantos casos de mujeres que sufren trastornos conversivos, somatizaciones, fibromialgias, trastorno de la alimentación, en muchos de los casos, es muy difícil para ellas y para los profesionales discernir sobre las causas de su padecimiento, y por ende, dificulta la eficacia del tratamiento, más aún en los casos que no hay correspondencia a una causa orgánica ${ }^{3}$.

La práctica del arteterapia con mujeres me ha enseñado el potencial del arteterapia como un medio para acceder al mundo interior mediante la expresión creativa, y entre sus funciones, las posibilidades como desencadenante para facilitar: el reconocerse mediante las obras artística; el identificarse entendiendo la obra como_"espejo", como "huella", o "marca" única de su singularidad subjetiva; el pensarse a través de la expresión creativa; el crear un sentimiento de pertenencia fuera de la heteroasignación; el identificar "sus deseos, sus necesidades", entenderse a sí misma; y el arte como autoría para empoderar la subjetividad.

Todos estos procesos resultan ser muy difíciles de conseguir cuando el proceso de construcción de la identidad ha tenido lugar mediante una construcción carencial. En dichos casos, estos procesos se convierten en procesos menos amenazantes, tal y como cita (Omenat, 2006: 244):

"La imagen muestra significados sin fijarlos y el/la paciente puede sentirse menos amenazado que con interpretaciones verbales que lo impliquen directamente. La imagen es más directa pero también permite más "escondites" porque trabaja desde la metáfora".

Algo que he podido aprender mediante la experiencia profesional en el trabajo arteterapéutico con mujeres, es que no hay angustia mayor que no saber quién se es, no ser o ser desde la mirada del otro. Tal y como cita (Levinton, 2003: 69): "Siglos de ocupación conducen obligadamente a la mujer a un trabajo de desalojo.

En este proyecto se les invitó a las mujeres del Hospital Virgen de las Nieves del área de salud mental de Granada, a hacer un trabajo de "desalojo" para emprender juntas un camino hacia el encuentro con la expresión, a adentrarse al descubrimiento de los lenguajes del cuerpo, a hacerse un "regalo a ellas mismas", a llevar a cabo una exploración donde no siempre estuvo solo presente el dolor, el sufrimiento, la angustia, sino también, estuvo presente la posibilidad de un espacio donde pudieron

\footnotetext{
${ }^{3}$ Enfermedades somáticas funcionales.
} 
encontrar y construir un lugar propio para permitirse ser ellas mismas. (Pain, 2001: 3) habla que una de las funciones del arteterapeuta es:

“...Un acompañamiento en la aventura de crear y descubrir cuál es el obstáculo inconsciente que le impide llegar a dar forma a su pensamiento y consigo mismas/os" “... Conseguir incentivar la capacidad perdida de resonancia corporal armónica sensorial y afectiva"..."No se trata de sacar a la luz sus traumas sino renovar la capacidad de hacer con ellos, que pueda dar sentido al mundo donde vive y hacerlo interesante para ellos/as mismos/as y para los otros."

Desde esa posibilidad del arteterapia para dar un sentido a sus creaciones, y que signifiquen algo interesante para ellas en relación a su identidad, ha permitido en estos estudios de caso disminuir la sintomatología de los estados de enfermedad. En un mundo donde la enfermedad era la bandera del cuerpo, el poder construir una percepción creadora en relación a su conflicto, le ha ayudado a dar un significado a sus vidas, a resignificarse, y a habitarse parcialmente en su propio cuerpo.

\section{ENCUADRE}

Centro: Hospital Virgen de las Nieves, área de salud mental. Es un hospital público, desde el área de salud mental delegaron a pacientes que habían sido previamente atendidas a los talleres de arteterapia.

$\mathrm{N}^{\mathrm{o}}$ total de talleres: 21 .

Duración de los talleres: dos horas y media, dos veces por vez por semana.

$\mathrm{N}^{\circ}$ de participantes: 9. Las mujeres tenían una edad comprendida entre los 40 a los 55 años. Todas están diagnosticadas del síndrome de fibromialgia y según los casos, presenta cuadros como: esclerosis múltiple, colon irritable, problemas estomacales, operaciones de miomas, depresión, angustia, trastornos conversivos...

Tarea: Permitir que las participantes trabajasen creativamente para alcanzar los niveles más altos de expresión, dentro de sus respectivos marcos físicos y psicológicos. Entender el espacio de arteterapia como un espacio de regalo hacia ellas mismas, un espacio destinado para pensar en ellas.

Estrategias para recoger la información: registro cualitativo, cuestionarios, entrevistas semiestructuradas, grabadora, notas de observación de los talleres, diario artístico por parte de las participantes, análisis de las obras, análisis de la asociación libre de la palabra en relación a los procesos creativos y objetos resultantes. 


\subsection{Estudio de caso}

\section{Presentación de RP:}

RP es una mujer de 41 años. Es la mediana de tres hermanos. Tiene un hermano mayor de 44 años y una hermana menor de 39 años. A la edad de 10 años perdió a su padre, quien murió de un infarto mientras trabajaba en el campo. Se sentía muy unida a él, a quién veía solo tres meses al año debido a que trabajaba en Francia y estaba siempre viajando. Desde la muerte de su padre califica su vida como un infierno. Dice haber recibido maltrato físico y psicológico por parte de la madre. Cuando se le pregunta en la entrevista cómo definiría a su madre dice acongojada: "fría, muy fría"; "yo no fui querida, yo no fui buscada...". Para ella su madre ha sido una persona que no transmitía afecto y por quien ella ha sentido una falta de cariño a lo largo de su vida. Desde pequeña ha vivido bajo la percepción de que al ser la mayor de las niñas tenía que hacerse responsable de sus hermanos, la casa, etc...También dice con pesar que nunca perdonará a su madre por haberla sacado de la escuela y privarle de la oportunidad de tener unos estudios y que nunca entenderá porque todos los palos iban a ella y a sus hermanos no.

A la edad de 16 años decide dejar el hogar materno porque no puede soportar más la convivencia con la madre, y su marido, entonces su novio, le ofrece irse a vivir con él y su familia. Un año después deciden casarse y años posteriores tuvieron dos hijos varones, actualmente de edades de 24 y 15 años respectivamente. Ha tenido dos intentos de suicidio, el $1^{\circ}$ al poco tiempo de ser diagnosticada por el síndrome de la fibromialgia y el $2^{\circ}$ en el 2011.

Antecedentes de salud: sufre depresión, trastorno conversivo, ansiedad de somatización, parálisis de la cara sin causa orgánica; en el año 2000 fue intervenida quirúrgicamente para tratar obesidad mórbida, desde la muerte de su padre ha sufrido trastornos alimenticios. Cuando fue intervenida pesaba 115 kilos y se quedó en 60 kilos, actualmente tiene anemia, recogiéndose en la entrevista cualitativa que sigue teniendo problemas y alteraciones en la alimentación. Confirma que desde que fue intervenida para reducir peso, aparecieron los síntomas de la fibromialgia y se le acentuaron otras dolencias que ya tenía. En el 2005 fue intervenida para tratar una gastropatía vertical. También fue intervenida por un mioma endocrino, en el 2012 fue intervenida de nuevo por infecciones y dolores en la vagina. Sufre el síndrome de la fibromialgia desde hace 20 años y fatiga desde que tenía los 16 años.

El estudio de caso de RP se va a dividir en cuatro fases. Los nombres que aparecen como título en cada una de las fases y la división de este trabajo en cuatro fases, siguen el criterio que la misma participante escribió en su diario artístico sobre las conclusiones que ella había extraído al observar sus obras y al reflexionar sobre el trabajo realizado durante las 21 sesiones. 


\section{FASE $1^{\text {a }}$ : DOLOR}

En los primeros talleres RP tendía a trabajar de manera muy rápida, de pie, hablando constantemente con las compañeras. Miraba el trabajo de las compañeras, se metía con la manera de trabajar de ellas, hacía mucho ruido, llamaba la atención, estaba muy tensa, dificultaba el acceso a un proceso creativo óptimo para la concentración.

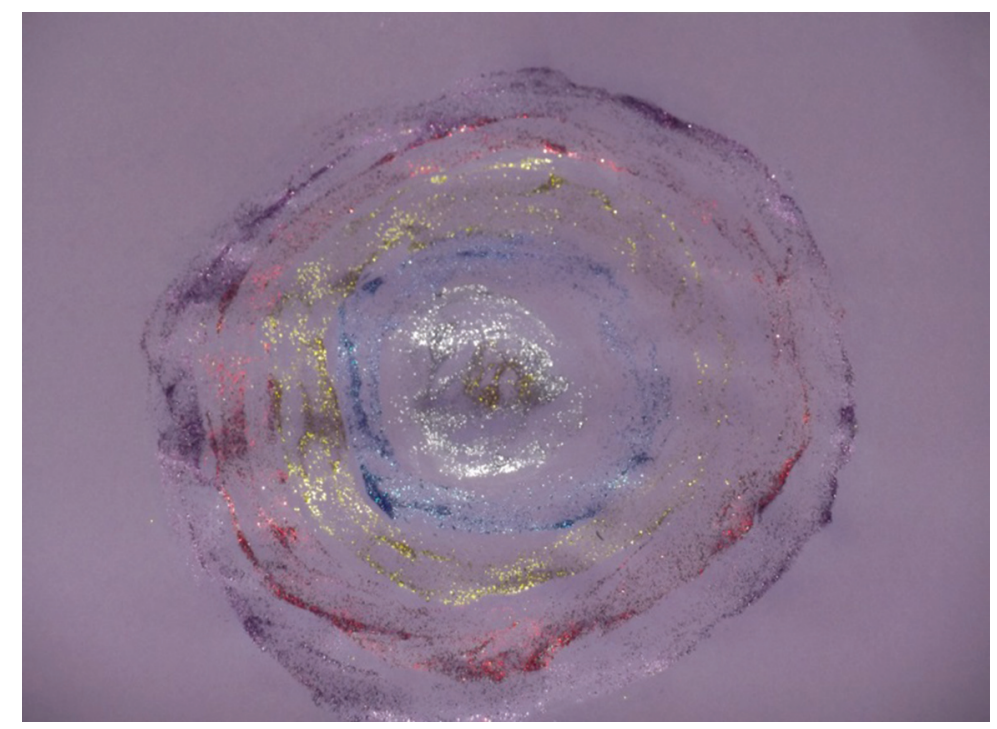

Imagen 1. Espiral.

Materiales diversos: lápices, ceras, rotuladores, cartulinas, folios, sacapuntas, bolígrafo, algodones, purpurina, cartulinas, telas, agujas, lanas, papel higiénico. Propuesta: "hacer una presentación".

RP dijo:

"Es una espiral cerrada, en el centro está lo más importante para mí, mi marido y mis hijos. Color plata, después viene el color azul, que representa "llega el día", afrontar el día. Los colores y capas posteriores viene a ser las dificultades, hasta que la última capa, la cual es la que no soporto y la que me quiero quitar de en medio". Título: "Ser feliz".

Llama especialmente la atención el material seleccionado. Por un lado, la purpurina le permite crear la obra desde un contacto directo con sus propias manos, y por otro, los límites de los diferentes círculos son como evanescentes, diluidos. No hay una correspondencia entre la palabra y la imagen. Otro aspecto significativo la relación de su identidad ligada como persona y mujer, directamente a la familia (su marido e hijos). 


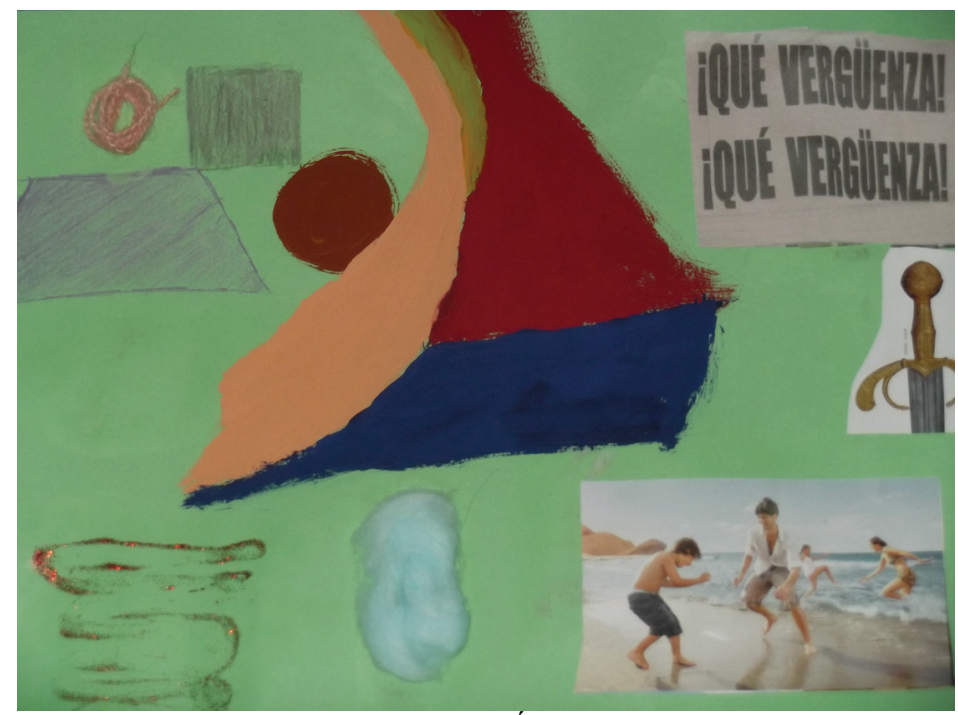

Imagen 2: Ánimo

Material: lo mismo que el taller anterior más revistas. Propuesta: Collage.

Hay cambios principalmente en el proceso de la creación. En este taller se concentra más en la tarea y favorece un espacio para el silencio y el trabajo. Algo llamativo, es que pinta de nuevo la espiral, pero ahora de manera diferente tanto en la forma de la misma, como en el proceso de realizarla, se la podía observar que estaba disfrutando mientras la hacía. La espiral de la imagen 1, era cerrada y ahora la representa desvaneciéndose, como en proceso de transformación. También es especialmente significativo la estética de la obra, parece transmitir como una sensación de peso, debido a los bloques de colores oscuros y más claros que hace en la parte de arriba del formato y las palabras que recorta: ¡QUÉ VERGÜENZA!

Los otros fragmentos de la obra aluden a la familia. Representa una imagen idealizada de la familia y en líneas generales, RP compara su obra con el Arte Contemporáneo, decía que su deseo era poder ser más libre, desinhibirse, fluir, "soltarse la melena".

Para RP lo más importante de su vida es la familia que ella ha construido y lo que más le ha marcado en su vida y en su salud es la familia donde ha nacido. Escribió en el diario artístico:

"A la próxima reunión mi estado anímico era más alto que en la anterior y ya que se había hablado en la anterior de cómo nos encontrábamos y procurando entender que mi vida no era tan fatal como yo creía y me sirvió para estar menos tensa y a raíz de esto mis dolores no son por ahora tan fuertes y no estoy tan tensa". 


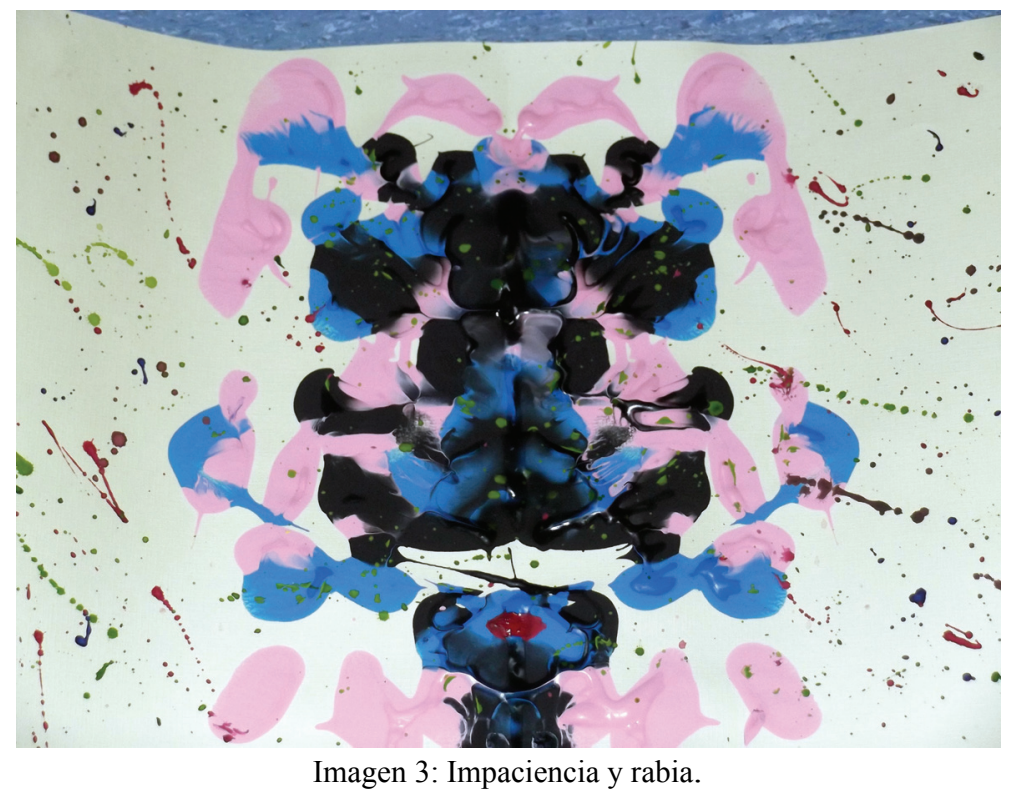

"Me ha hecho sacar mi parte oscura y a mi parecer de maldad o más bien de rabia y dolor que llevo dentro de mí y necesito expulsar. Me ha hecho recordar malos momentos de mi vida, en concreto de la infancia y la adolescencia que no he tenido porque me la robaron y que a la vez quiero olvidar y salir de ese cerco que llevo a mis espaldas y en conjunto en todo mi cuerpo, dejando siempre esa pequeña puerta abierta".

A través del arte los impulsos destructivos pueden ser gráficamente expresados, hechos conscientes, y así transformados en una personificación creativa. (Schaverien, 1999)

En la $1^{\circ}$ Parte del taller se trabaja con la relajación: relajar diferentes partes del cuerpo y con la figura del observador, después se trabajó con música, baile y con el acto de "parar" en un momento dado para observar las posiciones de nuestro cuerpo.

Propuesta: Ripping. Pintura de goteo.

Materiales: acrílicos, témperas, botes de cristal, bandejillas, papel higiénico, toallas.

En la puesta en común de las participante de su proceso creativo afloraron diferentes tipos de sensaciones y emociones a nivel grupal como: vergüenza, malestar, inquietud, agresividad con el material, silencio, ahondamiento en una misma, confusión, la necesidad de ser queridas y la hostilidad sentida de los vínculos cercanos, el malestar vivido por la relación en pareja, y sobre todo la angustia, de no 
poder ser como eran antes, mujeres que estaban para todos y lo hacía todo...Pero también hubo momentos de bienestar, relajación y respeto. El grupo pudo sostener las diferentes respuestas y reacciones llevando a cabo la tarea, en un espacio contenedor que permitió acoger la diferencia mediante el juego simbólico de la creación. RP dijo:

"Creo que no tengo ni que decirlo, aquí es mi mitad negra, mi parte mística, mala, la ganas de enganchar a alguien, y ¿me entendéis? este sería mi mitad rabia, de mi enfermedad, de considerarme que no valgo, que no sirvo. La oscuridad del negro, y el querer resurgir, el círculo mi familia, mis niños y el amarillo, lo he dejado abierto, estoy empezando a dejar huecos. He pasado un año muy malo y ahora digo que valgo, a tirar adelante, pero que mi parte negra está ahí. Yo era un bicho malo, y toda la gente me dice está la RP de antes, y les digo que se callen que tengo miedo a recaer. Quiero resurgir, pero también está mi parte negra. El amarillo, rojo es vida, sol. Me he sentido muy bien hacerlo, me gusta mucho la pintura, lo desigual."

En este fragmentos me gustaría detenerme un momento para poder pensar la relación que ella establece de "valía" y de "servir o no" en relación a temas (lo citará en un fragmento más abajo) como las labores de la casa, al mantenimiento del cuidado de la familia...Y posteriormente, en una entrevista semiestructurada hablará de la frustración y conflicto interior que siente al no poder responder como madre para atender a sus hijos, el cuidado de la casa y como mujer para satisfacer sexualmente a su marido.

Parece establecerse una relación entre la categoría de valía de una misma con unos atributos asignados socialmente a la mujer, unido a conflictos traumáticos procedentes de su novela familiar. Los estudios de la subjetividad femenina analizan un constructo social denominado "ideal de la mujer" sobre el cual, (Tavora, 2012: 3) dice que toda aquella mujer que no se adapta a ese ideal, puede estar expuesta al conflicto, a la culpa y puede afectar a la salud. Para la autora, eso es así porque existen mecanismos muy sutiles para que la persona haga suyo esa construcción social. El poder plantea una manera de ser que te vende como buena y tú la interiorizas. Estas premisas se traducen en ideas como que,

“...ser buena equivale a no sentir agresividad, ser madre equivale a organizarse desde el amor y la importancia de los afectos y ser esposa supone controlar la sexualidad".

La autora considera que esos valores llevan a las mujeres a priorizar la relación con los otros como clave en su construcción como sujeto, lo que dificultaría el proceso de subjetivación. 
Conforme avanzaba los talleres RP tenía más y más necesidad de hablar de cómo se sentía en relación a su obra. Dijo: mi obra representa "mi cara de odio", "mi lado malo". Conforme iba hablando se iba poniendo más nerviosa, angustiada, hasta que estalló en llanto y dijo:

"Yo me consideraba una mierda, que no valía nada, que iba hacer daño, que le hacía daño a mi gente por no tener la casa bien hecha, la ropa planchada...y ha sido considerarme mala, y...sentir que ellos no tenía culpa de ellos. Ver a mi marido que venía cansado del trabajo y tener que ponerse hacer cosas de casa. Y yo me he maltratado a mí misma mucho y me estoy dando cuenta ahora, y al maltratarme a mí he maltratado a mis hijos. Mi hijo pequeño esté en un internado por quitarle que me viera, de estar siempre mal, y en cambio mi hijo grande lo está pasando muy mal. Y me doy cuenta que los he maltratado, porque no tienen culpa de nada, ni yo tampoco porque no he pedido tener esta enfermedad, pero mi hijo grande lo está pasando muy mal, y esta todo el tiempo mirando el rabillo del ojo para a ver como estoy y no me estoy portando bien con ellos ni conmigo misma..."“...De pequeña sufrí maltrato por mi madre, yo no podía aguantar más ver que me trataba a mí diferente a mis hermanos...Ahora mi madre quiere acercarse a mí, pero es tanto el odio que ya no me sirve..."

Por un lado, podríamos recoger: sentimientos de ambivalencia y carencia afectiva de los vínculos fundantes como huella originaria del trauma, una construcción de un apego desorganizado; y por otro lado, podríamos reflexionar, por los datos que ella cuenta en la etapa de su infancia en relación al poco afecto y cariño recibido, en el modelo internalizado de objetos internos construidos, y como la participante ha podido experimentar múltiples abandonos por los objetos internos (padres). A modo de reflexión, quizás, al no encontrar un vínculo sustentante en la relación con la madre es lo que posiblemente le hizo a RP idealizar al padre, a quien en el corto periodo de vida que vivió, encontró un aliado. Pero la muerte repentina del padre, confrontó a la participante con otro suceso traumático, tal y como ella citó en una de las entrevistas "mi estado de ánimo empezó a desequilibrarse desde la muerte de mi padre".

Podríamos pensar en la idea de que la participante presentaba un complejo de Edipo sin elaborar, que reaparece en la pubertad, edad a la que conoció a su actual marido y dentro de la reflexión, podríamos pensar en la función que desempeñó su marido como función paterna, de sostén y contención ante los múltiples abandonos vividos $\left(1^{\circ}\right.$ por los padres y $2^{\circ}$ por la familia, al tener que responsabilizarse ella del sostén de la familia, dejar la escuela, asumir las responsabilidades y adquirir el rol asignado por la madre...).

Un hecho que podría reflejar un duelo patológico sin elaborar hacia la muerte del padre, son los episodios narrados por la participante en la vida adulta, por ejemplo: encerrarse dentro de una habitación oscura con la fotografía del padre y llorar durante 
horas. Estos episodios continuados y repetidos en el tiempo, podrían ser una fijación a la historia del pasado en la que ella vuelve a revivir el dolor y el sufrimiento de la pérdida.

$\mathrm{Si}$ nos detenemos a observar la obra, es especialmente llamativo lo ilustrativamente que representa lo que ella denomina "las sombras", "la oscuridad del negro", y las relaciones que va estableciendo de esas manchas con emociones como: el dolor, la maldad, el sentimiento de culpa.

Diversas investigaciones realizadas por el grupo de investigación de las Mujeres de las Palmas (González de Chávez, A., 2010: 16), afirman que:

“...las mujeres con diagnóstico de fibromialgia o las víctimas de violencia física y/o psíquica manifestaban de modo significativo haber vivido muchas carencias y/o sobre exigencias en la infancia, haber tenido muy malas relaciones con uno o ambos padres, haber sido testigos o víctimas de malos tratos y abusos sexuales en la infancia... La vivencia de estas experiencias y relaciones paterno-filiales contribuyen a horadar la confianza en sí misma de la persona que las sufre; a generar, a causa de las frustraciones y el rechazo recibido, sentimientos agresivos que son autocensurados (es decir, normalmente no expresados, como prescribe el modelo ideal de feminidad vigente, a diferencia de cuanto sucede con los varones); a acentuar la sensación consecuente de "ser mala", todo lo cual genera sentimientos omnipresentes de culpabilidad".

Otro aspecto relevante desde mi punto de vista que aparece en este taller, fue la reflexión que tuvo lugar dentro del grupo a raíz de lo que RP cuenta en relación a la toma de conciencia hacia el maltrato que se hacía así misma. Cuando RP describió las diferentes maneras de auto maltratarse así misma, posibilitó que las participantes hablasen de cómo y cuándo se sienten ellas maltratadas por ellas mismas, por ejemplo: cuando se sienten inferiores para hablar en público, cuando no se valoran si las otras personas no la valoran, cuando necesitan que sus parejas le den cariño para sentirse bien con ellas mimas, cuando no pueden tener la casa perfecta, planchar al marido la ropa, etc... Y asimismo, iban estableciendo la relación existente entre dicho maltrato hacia sí mismas, con el dolor y la enfermedad. Hernando expone que:

"El modo en que las mujeres internalizamos, actuamos y reproducimos un conjunto de valores y actitudes a través de las cuales nosotras mismas contribuimos a perpetuar esa situación de desigualdad respecto a los hombres" (Hernando, 2000: 10).

En el espacio del taller se reflexionó si podían permitirse no ser perfectas, ni cumplir el ideal de mujer, (intentar encarnar el ideal de mujer puede significar muchas cosas que promueve una invisibilización y anulación de la diversidad real de la mujer) y dicha reflexión, les conducía a la misma pregunta, la cual, quedaba 
siempre sin respuesta: ¿por qué antes yo podía con todo (la casa, los hijos, la familia) y ahora no?, ¿por qué antes yo estaba para todos, siempre para cuando alguien me necesitase y ahora no puedo?, ¿por qué...? , preguntas que las podríamos traducir en otra como ¿por qué estoy vacía?...parece que su narcisismo dependía del "servicio de los otros", pero no era suficiente para sentirse bien y su cuerpo habla de ello.

Algo especialmente llamativo en las conductas de una gran mayoría de las mujeres diagnosticadas de fibromialgia, (hallado en los estudios de caso que he trabajado) y en la literatura, es que se definen como "muy perfeccionistas" (González de Chávez, 2010: 17)

“...en más de un $60 \%$ de los casos, y que frecuentemente usaban las expresiones "yo hacía todo", "yo era todo para ellos", "todo dependía de mí", "yo lo tenía todo perfecto", expresiones que, por otra parte, reflejan el afán de totalidad, de completud, de (omni)potencia, que late tras el deber/deseo de perfección. Son las dos caras de una problemática (el goce y las sombras): la gratificación inconsciente de ser una omnipotente/perfecta cuidadora y el coste que se paga por ese afán, es decir, el malestar físico, el cansancio, el dolor."

En definitiva, este maltrato hacía sí misma que se nombra dentro del grupo, pondría en evidencia la autoagresión a través de los sentimiento de hostilidad reprimidos. Se les preguntó durante las dos primeras fases del taller, si la manera en cómo vivían antes: siempre corriendo, haciendo cosas para los otros, hiperactivas, exigiéndose ser un diez en todo lo que hacían, si ese estilo de vida era bajo su punto de vista "sano". Poco a poco, se iban dando cuenta, que la manera en como gestionaban sus emociones tanto en el pasado como en el presente no era saludable. En el pasado, tenían una fuerza física y corporal para llevar a cabo innumerables tareas, pero no tenían tiempo para dedicárselo a ellas mismas, a sus deseos y necesidades. Ahora la enfermedad ha sido como muchas veces citan ellas un "parar", que le ha impedido a nivel físico llevar ese estilo de vida, pero que les ha "obligado" a detenerse para parar un tiempo para dedicárselo a ellas mismas. Se les preguntó también ¿desde cuándo consideraban ellas que estaban con síntomas perjudiciales para su salud?, y ¿desde cuándo se pudieron haber dado cuenta de que la fibromialgia podía ser un resultado o constatación de algo que ya estaba establecido muchos años antes del malestar actual?, "no estoy mala ahora, llevaba mucho tiempo mala" (participante del grupo). Se abrió el debate de si la fibromialgia podría ser una oportunidad para actualizarse, reubicarse, reconectarse con ellas mimas. Todas llegaron a la conclusión afirmativa que la fibromialgia les había obligado a parar físicamente, pero que también les ha permitido trabajarse y ampliar el acceso a su área emocional.

En los talleres de arteterapia estuvimos trabajando hasta su final, con uno de los objetivos establecidos de cómo poder aceptar quienes somos, cuales son "mis 
deseos", "mis necesidades", desde un acompañamiento para la identificación de los mismos, hasta un sostén para poder empoderarlos. Ha sido un trabajo que se ha ido tejiendo arduamente durante las sesiones de los talleres para poder trabajar en la desidentificación asignada como mujeres y acercarse a los deseos y necesidades propias que posibilitasen la construcción de un sí mismo menos "alienante".

Al finalizar el taller de la imagen 4, RP hablaba de su historia familiar, compartiendo secretos muy dolorosos y finalmente dijo: "El día que me veáis con colores cálidos podréis decir: ha resurgido la RP de Mayo".

\section{FASE 2. DESCUBRIR NUEVAS SENSACIONES}

Materiales: soporte para acrílico, acrílicos, pajitas, palillos de dientes, pinceles.

Proceso creativo: se trabaja con las pajitas y acrílico. Consiste en soplar con la pajita los colores y desde ahí pintar lo que nos surja.

Me gustaría describir como venía la participante este día a los talleres desde la comunicación verbal como desde la comunicación no verbal.

RP llega al taller llorando, se encontraba muy mal, le acababan de diagnosticar esclerosis múltiple, dice que pese a todo necesitaba venir al grupo, estar con sus compañeras, porque siente que en el grupo puede ser ella misma. Las compañeras en general la acogen. Pero quizás podía conmover más la comunicación gestual de ella, la postura de su cuerpo rígido, (como si tuviese un palo dentro del cuerpo); la postura del cuello, un cuerpo muy limitado por el movimiento. Una mirada rota de haber llorado, una queja continua, una negación ante cualquier atisbo de vida, y pidiendo mediante la queja del dolor $\mathrm{y}$ sufrimiento un cálido abrazo y cariño. Afortunadamente, parecía encontrar en una de las compañeras "a la madre que nunca tuvo" y estoy segura que esta función que desempeñó el grupo de "sostén", de manera simbólica a lo que Winnicott denominó la "madre suficientemente buena", fue clave para permitirle a ella trabajar y llevar a cabo la tarea. 


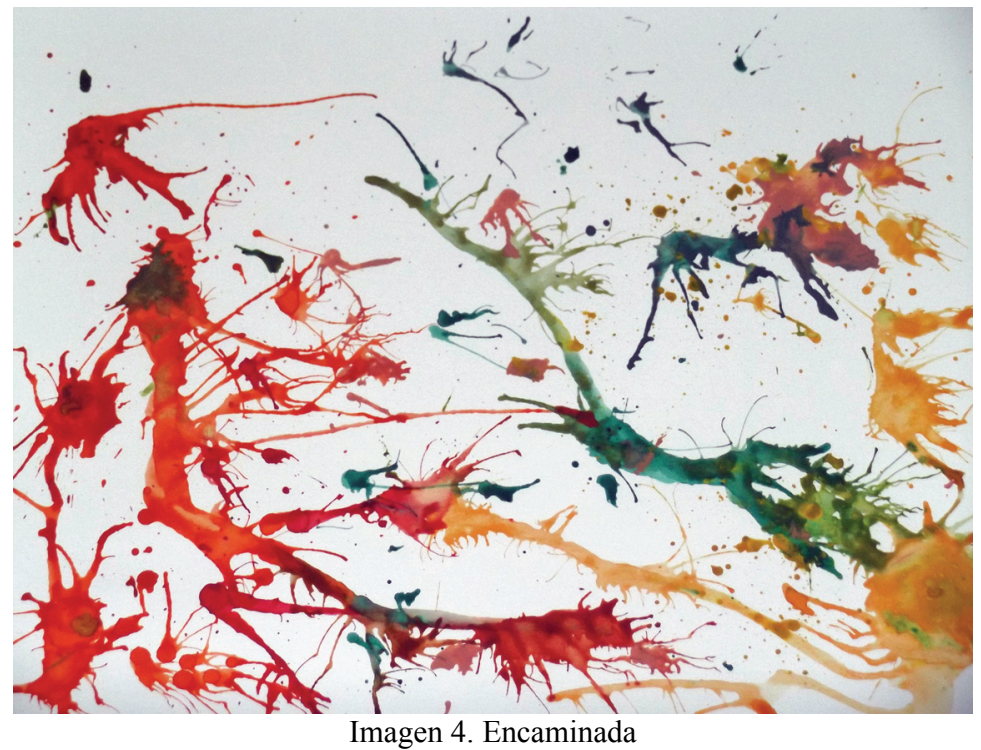

Algo especialmente llamativo durante la sesión fue ver su proceso creativo, cómo iba creando esta obra desde el dolor y el malestar que traía. Al inicio le costaba mucho empezar, se quejaba, tenía que parar e interrumpir con continuidad el proceso, resoplaba. Me miraba como diciendo no voy a poder terminar la obra, pero no desistía y entre las constantes paradas iba primero jugando con las pajitas a expulsar pintura y después a crear forma con las gotas de la misma. No utilizó ningún otro instrumento más que las pajitas y el color. Poco a poco, conforme se disminuían las paradas y aumentaba la concentración y se dejaba llevar por el juego, se podía observar cómo se iba destensando, dejando a un lado el dolor y dedicando una completa entrega a la obra. Se la veía menos fatigada y más liberada, ha ido como sacando un peso de su cuerpo.

Escribió en el diario artístico:

"Al principio no me encontraba a gusto con el taller que nos propusieron pero poco a poco empecé a encontrarme como liberada y como encontrando caminos de escapada de todo y de todos mis miedos, dolores, indecisiones y muchas sombras oscuras que tengo en mi mente. Me han diagnosticado esclerosis y con mis compañeras me sentí arropada y comprendida y un poco aliviada".

Una de las compañeras le dijo: "Hoy eres tú misma, sin tu marido, sin tus hijos, sin tu familia. Quédate así más a menudo". Ella y el grupo se rieron. RP respondió: "Si, hoy puedo decir que soy yo misma". 
A nivel grupal podía observar que parte de la mayoría de las participantes estaban llevando a cabo la tarea y estaban en un proceso de lucha interna, sintiendo una soledad ante el hecho de tener que enfrentarse a dificultades, sobre todo, el símbolo de la mariposa fue uno de los temas comunes en el grupo. Algunas hablaban de la necesidad de transformar emociones y otras de estar experimentando como una muerte simbólica de una parte de ellas mismas y el renacer de otra parte, la cual, le asustaba porque aún la desconocían, o era la primera vez que se acercaban a esa parte de ellas mismas. Pero otra parte del grupo, paralelamente, presentaban resistencias a trabajar la tarea y sobre todo a la fuerza del grupo. El grupo estaba teniendo una dinámica orientada a generar cambios y parte del mismo, manifestaban bloqueos, resistencias, desconexiones a lo que se trabajaba y poco a poco, dos de ellas lo fueron abandonando. En ésta $2^{\circ}$ fase evolutiva tuvo lugar la salida de unas de las compañeras del grupo. La ausencia empezó a teñirse de otros matices como "la dificultad que se puede presentar el tener que hacerse cargo del proceso de subjetivación", "la dificultad para poder recoger lo que se ha comunicado o cómo aquello que la compañera nombra atraviesa mi propia herida". En esta fase, la ausencia tenía un lugar dentro del grupo como una "resistencia", la ausencia como esa "alianza" a la fibromialgia para evitar situaciones dolorosas. ${ }^{4} \mathrm{Y}$ la ausencia también como "mecanismo de negación", por el que no se quiere ver que la fibromialgia tiene que ver con el cuerpo y también con la psique, con la historia personal, con el mundo emocional, si todo está en el cuerpo y el tratamiento es médico, entonces me coloco en un lugar de víctima y no pudiendo hacer nada para cambiarlo, lo que se podría relacionar con el beneficio secundario de las enfermedades psicosomáticas. Pero me gustaría ir un poco más allá en esta dificultad y poder poner en relieve como los mandatos de género pueden dificultar aún más en este colectivo el acceso: primero, a la identificación de los conflictos que están bloqueando e influyendo en la estabilidad emocional; y segundo, a los recursos para poder gestionarlo. Tal y como cita (Coria, 2005: 29)

"La organización de nuestra sociedad patriarcal ha preparado durante siglos al género femenino para transitar por la vida al servicio de las necesidades ajenas. Desde pequeñas, las mujeres aprenden a entrenarse para descifrar los deseos de quienes las rodean, primero los padres y las personas de su entorno, luego sus compañeros amorosos y finalmente sus hijos/as. De tanto profundizar en los deseos ajenos, suelen perder la habilidad para descifrar los propios $\mathrm{y}$, de tanto acomodarse para satisfacer aquellos, terminan haciendo propios los deseos de otros (...) no son pocas las mujeres

${ }^{4}$ Situaciones carenciales afectivas y formaciones traumáticas en la infancia, el trauma impide la construcción del yo, y se producen bloqueos emocionales. Mediante el bloqueo se evita una parte del sufrimiento. Otro modo de evitar el sufrimiento es mediante las somatizaciones que aparecen años después. Otro modo de evitarlo, mediante el aprendizaje a esquivar situaciones que las coloca en el dolor. 
que ven desplegarse ante sí un enorme desierto intransitable a la hora de buscar los deseos dentro de ellas".

Tras comentar en líneas generales la evolución del grupo, añadir que RP a diferencia de otras compañeras del grupo se encontraba en una fase de liberación, de expulsar rabia, dolor, de sacar todo eso que tenía acumulado durante tanto tiempo y a raíz de este taller, es cuando ella dijo empezar a sentir un "resurgir".

\section{FASE 3. LIBERACIÓN.}

Propuesta: escoger una obra, la que queramos y la vamos a romper y con ella vamos a crear una obra nueva.

Materiales: pajitas, témperas, plastilinas, lanas, lápices, ceras, rotuladores, cartulinas, folios, sacapuntas, bolígrafo, algodones, purpurina, telas, agujas, papel higiénico.

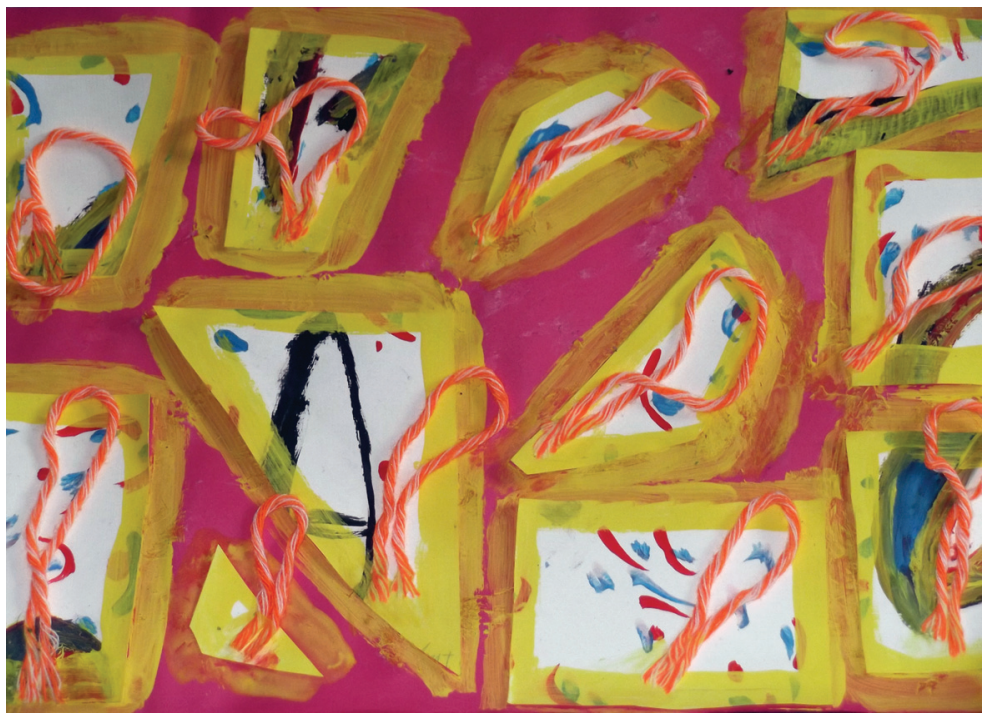

Imagen 5. La tranquilidad.

"Nos dieron la opción de coger una de las obras que habíamos elaborado a la que yo escogí "Maldad-Odio-Rabia". Nos ofrecieron destrozarla y elaborar a raíz de ella lo que sintamos en ese momento, yo decidí coger solo los espacios de color y libertad y enmarcarlos dentro de color amarillo y a la vez fui añadiendo un trozo de lana para significar que cuando tuviera un sentimiento malo tuviera en cuenta esa creación y por eso la titulé "Punto de atención" y me encontré bien al destrozar lo que antes había elaborado".

En el turno de palabra dijo no haber tenido duda sobre la elección de la obra, escogió esa obra que representaba su parte negra (imagen 3). Algo significativo fue cómo seleccionó la parte de color (sin negro) para reutilizarlo en la nueva obra, con 
algunos pequeños fragmentos del color negro, pero principalmente lo negro lo dejó apartado. Durante el proceso tuvo la necesidad de preguntarme si podía tirar lo que no quería de la obra que había roto a la basura, le respondí que tenía absoluta libertad para hacer lo que desease; rápidamente lo tiró a la basura. Después explicó que para ella eso que había tirado, representaba lo que la familia le había puesto a ella, y dijo: no quería conservarlo, no quería volver a ellos, no me encontraba bien con eso, y por eso lo he tirado a la basura.

Dado lo ocurrido dentro del espacio de taller, en el cual, la participante necesitó tirar esa parte negra que representaba una parte (muy negativa) que habitaba en ella, y los efectos de liberación y tranquilidad que ese acto le hizo experimentar, así como el cambio de posición subjetiva que se produjo en talleres posteriores, me permite recordar y reflexionar una de las conclusiones que desarrolló (Schaverien, J 1999, 44: 479-510) en sus tesis doctoral, en relación a la cuarta transferencia ${ }^{5}$ (chivo expiatorio).

El chivo expiatorio es un ritual ampliamente aplicado a lo largo de la historia, para la purga del mal y la enfermedad de una comunidad mediante el sacrificio de un animal, persona u objeto. La autora tiene la premisa que las imágenes pueden jugar un papel o un rol similar dentro del análisis. La disposición a ese material (expiatorio) puede darse en ocasiones mediante la destrucción de un objeto (como en este taller) o como se da más habitualmente que el arteterapeuta custodia la obra, hasta que el afecto encarnado pueda ser integrado en la personalidad del participante, (como sucedió en el taller de la imagen 3). La autora entiende el significado de "disposición" como una manera de poder "deshacerse de" (pecado, enfermedad, de lo que emerge del grupo). Para la autora, estos chivos expiatorios son representaciones conscientes basados en la visión filosófica del mundo que una "transferencia ${ }^{6}$ de "atributos y estados" pueden ser posible y al mismo tiempo curativo. (Cassirer, 1955). La idea que "atributos y estados" pueden ser vistos como substancialmente transferibles parece articular un aspecto psicológico de los procesos creativos. El arte ofrece un significado particular de transformaciones de estados psicológicos, de los cuales, de otra manera, no habrían podido ser expresados. Así podríamos pensar en el trabajo artístico de RP que una vez creado, pudo ser simbólicamente experimentado como un objeto que porta una transferencia de los aspectos de la "sombra" (tal y como lo cita ella) de su personalidad, haber hecho un trabajado desde las emociones que le ha generado el proceso de creación del objeto ("me ha hecho sacar mi parte de maldad, mi lado negro...") y la posibilidad de expiación al poner esa parte de ella en un objeto

\footnotetext{
${ }^{5}$ La autora siguiendo a Freud, Greeson (1967) divide la relación analítica en tres partes. Son: "la relación" real, "la alianza terapéutica" y "la transferencia".

${ }^{6} \mathrm{El}$ término de transferencia que utiliza la autora presenta similitudes con el proceso que envuelve en la creación de una obra de arte y sus conexiones con el concepto de transferencia en el psicoanálisis.
} 
y deshacerse del mismo. Cuando se habla de transferir, no es solo una sustitución simbólica, sino una transferencia física real. No es como si el chivo expiatorio portase el afecto o la enfermedad, sino que el objeto creado es transformado en una cosa con una manera muy concreta (imagen 3 y 5). El objeto artístico se convierte en un objeto de transferencia, donde afectos del pasado se viven en el presente, y le permite a la participante trabajar con ellos en el "aquí y ahora del taller" para llevar a cabo procesos de reelaboración del material inconsciente.

Lo que me ha permitido establecer una relación entre el chivo expiatorio de Schaverien, J y la participante, ha sido el observar los patrones de comportamiento, así como, de la autopercepción de sí misma (negativa, sin valía, con culpa...) que podían proceder de la forma en la que ha sido tratada, mirada, y reconocida. (Riviére, P 1985: 11) dice que: "cualquier situación de tensión particular que se desee investigar debe llevarse a cabo dentro del contexto social en que las cosas suceden, es decir, en el afuera" (ibídem). Podríamos pensar tomando como referencia la novela familiar de la participante, que ante el suceso traumático de la pérdida repentina del padre, la participante se convirtió en el chivo expiatorio, tanto en cuanto a las responsabilidades que tuvo que adquirir y como convertirse en el blanco de la diana para gestionar las dificultades familiares y consecuentemente, convertirse en el único miembro de la familia que enferma. La participante ha estado en conflicto con ella misma a edades muy tempranas. Por un lado, personificó el rol asignado por la madre; pero por otro lado, ha vivido su historia como una gran injusticia y aunque hizo el acto de separación física a edades muy tempranas, no lo había hecho aún a nivel emocional. Podríamos pensar en que uno de los problemas que parece manifestar tendría que ver con que no ha hecho esa distancia entre el otro y una misma, lo que (Amorós, 1988) define como "el recorte subjetivo del otro y de ti".

Un hecho significativo que tuvo lugar dentro de los talleres, fue a partir del comentario de una de las participantes, que le permitió hablar de un aspecto central de su sufrimiento dentro del grupo. Le dijo: "Tú estás llena de muros, solo tienes muros, yo no veo aperturas en ti".

A lo que RP contestó que ella lo que único que quería es que su familia (madre y hermana) cambiasen su actitud hacia ella. Siempre traía esta queja al grupo, la hostilidad experimentada por los Otros, el no recibir cariño, ni comprensión, el no ser querida, ni valorada y sobre todo, un sentimiento de una enorme injusticia al sentir haber dedicado su vida a su familia y ahora no recibir lo que ella consideraba que debería. Podríamos pensar que se activa la transferencia con el pasado, y cómo ella seguía relacionándose, con la hermana y la madre en relación a los modelos internalizados de los objetos internos, de la misma manera que seguía sin aceptar la muerte del padre. Podríamos observar como de una manera inconsciente transfería mediante la queja y hostilidad "esa falta" hacia la hermana, y como de una manera inconsciente la hermana encarnaba el papel de la madre. Le exigía a la hermana lo 
que la madre no le dio, le exigía que cubriera "su falta" y le recriminaba por todo lo que ha perdido. La respuesta de la hermana era de un rechazo absoluto, la evitaba. Esta relación entre ambas producía a la participante RP la actualización del conflicto traumático en la cotidianeidad. Con la hermana tenía disputas constantes, su relación se había agravado hasta el punto de que en el pueblo solo podía vivir una de las dos. Algo curioso es el hecho de que los dos hijos de la participante también están separados, uno vive en un internado (el pequeño), para evitar que sufra y viva los brotes de la fibromialgia y el otro (el mayor) es el que está en casa, cuidándola y viviendo de cerca el proceso.

Otro hecho significativo es como el trauma impide avanzar y hace repetir en su cotidianeidad aquello que no se elaboró. De una manera inconsciente está repitiendo en su núcleo familiar lo que hicieron con ella. Al igual que de manera repetitiva recrea esas emociones vividas en la infancia de no haber sido querida en el exterior, en otras relaciones familiares y sociales.

El espacio de arteterapia le permitió a la paciente reflexionar que fue muy injusto que a esa niña se le privase de lo principal que necesita un ser humano para su crecimiento saludable. Pero que aquello que no tuvo, ya nadie se lo iba a proporcionar, ni el marido, ni los hijos, ni la familia, etc... Es necesario aceptar, tal como cita (Levinton, 2009), que te quisieron lo que pudieron quererte y no más porque, en la medida que aceptes lo que no te dieron dejarás de pensar en las relaciones solo en clave de lo que te dan o no te dan y podrás descubrir nuevos aspectos de las mismas que no estén solo condicionados por la satisfacción de tus necesidades. A su vez hacer el duelo de que lo que no te dieron en esos momentos ya no podrán dártelo, o por lo menos no podrán dártelo de la manera que tú lo hubieses necesitado cuando eras pequeña.

Esa necesidad de sentirse querida se convierte para muchas mujeres en un organizador interno y un organizador externo. Hablamos de organizador interno cuando, en la medida que te sientes querida, te valoras a ti misma como sujeto, lo que Levinton, N. en Berrocal, M. L: 2011) llama la "narcisización del apego". La satisfacción de la necesidad de ser querida es a la vez también llave para otras necesidades, fundamentalmente de autonomía, de desarrollo personal y de seguridad básica.

Esa pérdida del amor que tantas veces refiere la participante en los talleres, la debía de elaborar por sí misma y que para ello, el espacio del arteterapia podía ser un medio muy útil para construirlo.

Un aspecto fundamental a tener en cuenta en el proceso de construcción del género, es la forma en que, a hombres y mujeres, se nos enseña a amar. De acuerdo 
con (Sanz, 1995): las mujeres aprenderían a amar para la fusión, es decir, poniendo el valor de una misma en la elección del otro. Mientras que los hombres sin embargo, aprenderían a amar para la separación, teniendo una identidad social con valor en sí mismo y reconocimiento por ser quien se es.

Como dice (Tavora, 2012: 197-204)

“...se ha construido una arquitectura sobre la mujer, que deviene de las miradas externas que van configurando una forma de constitución de identidad femenina «prevalentemente centrada en un ser para ser percibido, para ser mirado, tiene el efecto de colocarnos en un estado de permanente inseguridad corporal y simultáneamente, de alienación simbólica»".

Condición ontológica que según (Beauvoir, 1981) conduce a la mujer a ser para otros. Un deseo que nos llevaría a un tipo de relación fusional, donde el otro se convierte en el regulador de la propia angustia y que llevaría emparejada la renuncia del desarrollo de una misma como sujeto.

Durante las sesiones de arteterapia se le va confrontando mediante la expresión creativa, para que pudiera ver ese otro lado del muro de su obra, de sus muros internos, y pudiera pensar en cómo se podría sentir su hermana cuando recibía una responsabilidad y un peso que no le pertenecía a ella y que no podía entender. Y acercarla progresivamente a que su dolor no se debe tanto hacia la actitud de su hermana sino hacia "las necesidades, carencias y dependencias de ella hacia el Otro", posibilitó el poder renovar la capacidad creadora de sus fijaciones y conflictos. Hasta ahora no se podía cuestionar la posibilidad de poder ser autora de sus emociones. La enfermedad es como un laberinto donde existen salidas, y salidas falsas; la abnegación repetida de cubrir la falta mediante el amor y el reconocimiento del Otro, abocaba a un fracaso de todos sus intentos. El arteterapia posibilitó a través de la creación de las obras poder elaborar la parte emocional, poder simbolizarla. 


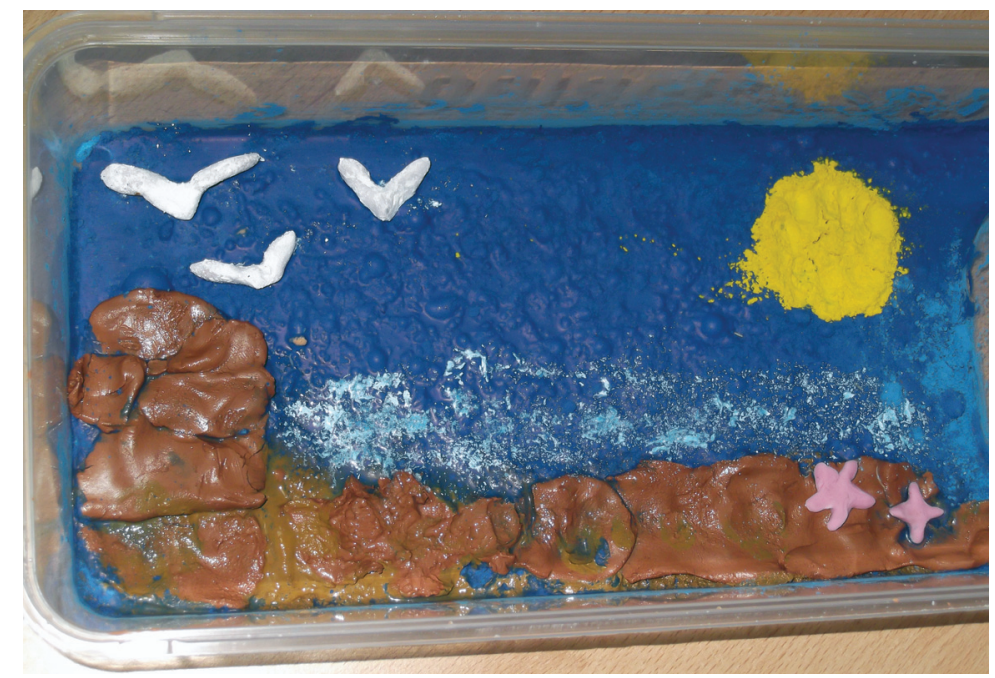

Imagen 6. Sola conmigo misma-Paz.

"Nos han propuesto elaborar con varios elementos un lugar, un momento o un sentimiento en el que nos encontramos bien. Mi obra la realicé con arcilla, plastilina y pintura. En ella realicé mi punto en el que yo me siento libre y tranquila. Mi obra fue un mar tranquilo, muy azul y un sol muy radiante con unas gaviotas revoloteando y una roca, en la que yo me siento sola conmigo misma sin nadie a mi alrededor".

En la tercera fase del proceso evolutivo, el trabajo arteterapeutico se centró en la identificación del núcleo de sufrimiento. ¿Por qué sufro?- Porque el otro no me quiere, no me entiende... (Participantes del grupo). Era muy significativo como las obras eran usadas como mediadoras para poder acercarse a áreas de dolor y mediante la observación de la misma, podían tomar conciencia de ese dolor emocional (existencial) que se podría diferenciar del dolor físico de la fibromialgia. Algunas de ellas eran muy ilustrativas y daban pista sobre cómo fracasaban en sus intentos de levantarse, y volver a caer en la depresión. Por ejemplo, se les invitó a hacer una obra sobre un espacio ideal para ellas. La participante RP trajo una foto de una revista, de una mujer joven, guapa, pintada, feliz, perfecta...decía que así era ella en el pasado. Colocó el recorte de esa fotografía en una esquina del soporte y el resto estaba coloreado de azul y vacío. A través de la obra creada, la participante pudo hablar de sus deseos por alcanzar aquello que no tuvo en la infancia (que ella relacionaba al éxito o fracaso de su felicidad), y desde ahí, este espacio le permitía hacer una parada para poder pensar en cómo esa manera de ver su obra, de construirla, de significarla podía ser como un espejo donde mirar el reflejo de su problemática. Todo el grupo y yo podíamos comprender mejor su discurso en relación a su obra, como intentaba construir un futuro desde ese ideal de encontrar lo que no tuvo en el pasado, que no existió y que además, fue un anhelo. Este parar para poder pensar en las devoluciones 
hechas sobre su creación, le permitía tomar conciencia sobre claves de la repetición que le conduce a un estado de enfermedad crónico.

En la tercera fase del taller RP empezó a comprender parte de la particular manera de querer afrontar su presente, mediante el pasado y parte de su sufrimiento en relación a cómo se relacionaba con los demás, principalmente desde "sus necesidades y su falta". Rivière, planteó la enfermedad como una cantidad de sufrimiento que el sujeto no puede soportar, siendo un sufrimiento que se está generando en las relaciones que la persona está teniendo. (Berrocal, 2011: 3) señala que "sufrimos cuando nos relacionamos y nos relacionamos a partir de nuestras necesidades, añadiendo en este punto la idea de la necesidad de ser querida".

Poco a poco, a través de la creación de nuevas obras le permitía por un lado tomar decisiones, ampliar nuevos puntos de vista, ya que todo el grupo comentaba sus impresiones y perspectivas sobre lo creado, y construir nuevos recursos tanto plásticamente como emocionalmente. Traer la repetición del conflicto relacionado con la enfermedad física, convertía el taller como un "lugar de laboratorio" donde poder explorar y reelabora la repetición, tanto plásticamente como verbalmente, y tras la recreación, se produce en cada una de las sesiones "nuevas repeticiones". Todo ello, de una manera progresiva, permitió a la participante construir otras maneras de relacionarse un poco más separadas a su falta originaria. Aprendió a acercarse a la hermana no tanto desde la recriminación, exigencia y culpa. En este taller concreto, la participante compartió con el grupo los cambios que había empezado a hacer. Había decidido dejar de esperar a que la hermana hiciese lo que ella necesitaba y había decidido ir al encuentro de ella y explicarle como se sentía. Inicialmente la hermana tuvo una reacción negativa, pero a los pocos días la hermana empezó a cambiar y empezó a acercarse más y más hasta que finalmente antes de que finalizasen los talleres, pudieron mantener una relación, en la cual, la participante le permitió tener una tranquilidad para poder pensar en ella misma, sin estar tan condicionada por la transferencia de los modelos internalizados. La relación tanto con la hermana y con la madre mejoró a lo largo del tiempo y paralelamente, disminuyeron los ingresos en urgencias por brotes de angustias y trastornos conversivos.

En otro taller posterior se trabajó con la propuesta de la caja, la tenían que trabajar tanto por dentro como por fuera. A esta obra la denominó la CAJA DE PANDORA. Es un ejemplo esclarecedor de cómo estos cambios que se están nombrando se van haciendo cada vez más sólidos. Algo significativo es el nombre que le da a esta obra: Pandora. En la literatura, Pandora responde al mito de la mujer que porta todos los males a la humanidad. La personificación de la culpa que encontramos a lo largo de la historia en la mitología Eva, Lili...Pero también Pandora, tal y como cuenta la leyenda, cuando abrió la caja sin permiso de Zeus y se escaparon todos los males, la cerró en el último momento y dejó algo dentro, la ESPERANZA. Creo que la 
participante nunca perdió la esperanza de una cura, de un poder encontrarse mejor y ha sido una persona que ha luchado mucho para poder salir de la encrucijada de la enfermedad.

Lo más ilustrativo en este tallar fue observar cómo trabajó la parte del afuera y la parte del adentro. La parte de afuera, escribió todo lo que la familia de origen le había dado: incomprensión, sufrimientos, dolor...y lo pintó de negro. Y por dentro, escribió las cosas que estaba aprendiendo: darse cariño a sí misma, quererse, valorarse y lo pintó de color blanco. Algo que ella puso en relieve como algo nuevo que había experimentado, fue que no había sido igual para ella pintar la parte de afuera (donde experimentó rabia, odio...) a pintar la parte de adentro, donde se estaba trabajando a ella misma, y lo hacía con cariño, con mimo. En el interior ha representado a la familia que ella ha construido, para ella es un una brújula, una guía hacia dónde ir.

\section{FASE 4. TRANQUILIDAD.}

En esta fase, se llevaron a cabo acciones más dirigidas. Se hizo uso de artistas que habían trabajado temas que tenían una relación a la problemática que se estaban abordando a lo largo del proceso: la dificultad para la separación, elaborar el vació pues el otro no va a suplir nuestra falta, poder asumir hacer un trabajo de subjetivación para construir otros recursos que faciliten una mejora en la gestión para el afrontamiento de la fibromialgia, y de las problemáticas concretas que estaban trayendo. Reelaborar las repeticiones en otras estrategias más saludables.

Se tomó como referencia a Louise Borgeouise, Richard Serra, Yayoi Kusama y Shirin Neshat.

Estas acciones artísticas tenían como finalidad trabajar uno de los objetivos del taller, el empoderamiento de la subjetividad femenina. Una vez ya identificada las problemáticas, (tras hacer un recorrido junto con la participante para la construcción de nuevos recursos y estrategias para poder afrontar el conflicto), se la invitaba a reflexionar cómo otros artistas marcados por una infancia traumática, hicieron uso del arte para poder reelaborar esa falta y esa pérdida originaria.

Uno de los talleres más significativos en esta fase fue el taller que se realizó a través de Shirin Neshat ${ }^{7}$.

La importancia de cómo el lenguaje nos puede marcar, inscribir e influir en nuestras emociones. Es una artista que trabaja con las inscripciones en el cuerpo. El

\footnotetext{
Esta propuesta fue presentada por (Fernández Cao, M. A, 2012) en el curso de "Arteterapia y Género: el arte para el acompañamiento y transformación”, celebrado en la Universidad de Granada.
} 
hecho de escribirse en el cuerpo puede ser una manera de como por el hecho de nacer, el lenguaje puede ser un mandato y el hecho de escribirlo en el cuerpo es un medio simbólico de poder reescribir nuestro lenguaje inscrito por la cultura que nacemos.

La propuesta del taller consistía en que cada una de las participantes se tomases un tiempo para pensar en una frase, palabra, símbolo o lo que deseasen, para representar lo que la sociedad o los demás sienten que les dice, o como deben: oler, pensar, sentir, ver, digerir, tragar, tocar, mirar, desear, querer...como sienten que los demás lo esperan $\mathrm{o}$ como han sentido que lo han tenido que cumplir. Consecuentemente, tenían que seleccionar una parte del cuerpo y representarlo. Por otro lado, tenían que representar los deseos propios en otra parte del cuerpo. Serían en total dos propuestas a pensar: como nos sentimos desde la demanda de los demás y cómo son nuestro propios deseos.

A la propuesta sobre lo que la sociedad o los demás nos dice, representó imposición y su deseo era la comprensión hacía así misma y de la sociedad hacia ella. Reaparece la problemática que estamos tratando a lo largo del escrito. La participante siente haber recibido una imposición hacia su persona y ella necesita reconocimiento (desea mediante "la comprensión") del Otro, más ahora estando enferma. Cuando se le pregunta que hace con sus deseos cuando el Otro no los reconoce, dice que "creo un muro u olvido mis deseos, e intento vivir sin el Otro, pero al final me produce frustración, al final me agredo a mí misma". Después citará: "yo creo que he avanzado, me he sabido enfrentar a mi hermana y a mi madre, parece que ese muro no ha caído del todo pero..."

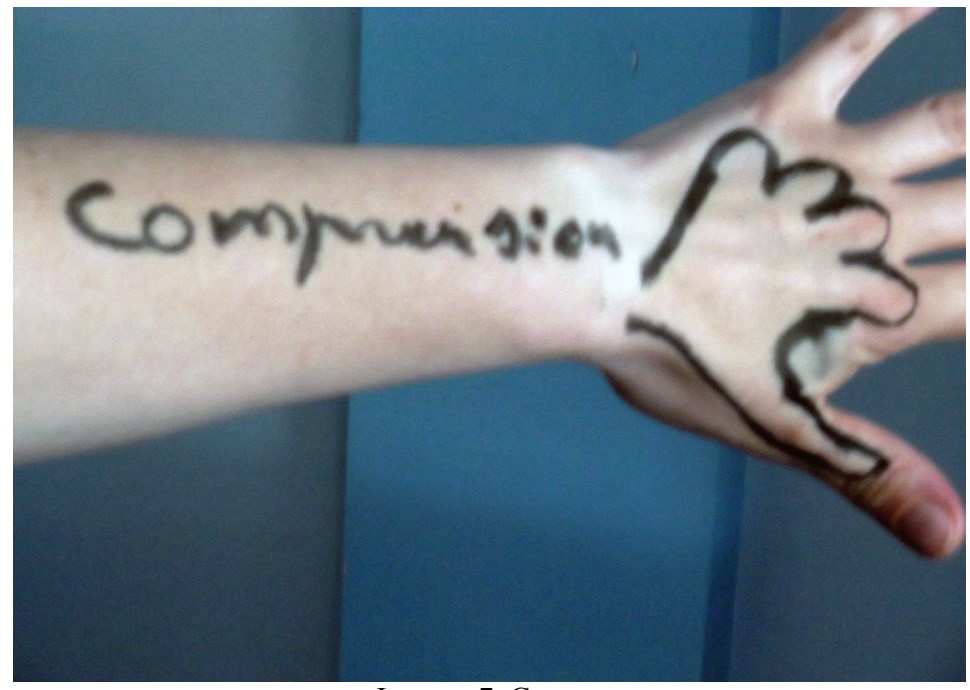

Imagen 7. Cuerpo 
El hecho de poder nombrar, comprender claves del sufrimiento y compartirlas en el grupo, favorece poder pensar nuevas modos de hacer. Uno de los objetivos del taller, es poder acompañar a través de la creación en la construcción de unas salidas "sanadoras" a la repetición, que le posibilite a la participante no volver a fijaciones del pasado, si no construir otras vías más saludables. Esta propuesta artística además de ser una propuesta simbólica para el empoderamiento de los deseos, trabaja con el sujeto que se reescribe en su cuerpo, para convertirse en objeto de escritura, para volver a ser sujeto que se observa desde afuera, por lo que ofrece a la participante de una manera indirecta diferentes pliegues por donde doblar la realidad, o diferentes perspectivas por donde poder pensar el conflicto y durante el tiempo de la sesión poder moverse entre la ambigüedad. Pensar en el conflicto, relativizándolo favorece la apertura del mismo y amplia nuevas posibilidades de entendimiento.

\section{PIRAMIDE:}

"Yo he puesto una pirámide de mi vida, el pico...luego he querido reflejar una puerta que abre esa pirámide, un camino, que quiero poder seguir... Es abrir una puerta a esa pirámide que se ha roto, que estaba cerrada, estoy predispuesta a abrir un camino, y decir no, no se ha roto, bueno si, se rompió pero volver a construirla".

"Ha sido un taller muy gratificante y agradable el estar expresando con tus manos lo que en tu mente existe. Fue agradable el quitar una parte de la parte principal y acoplarla al camino, expresando en ello algo que no me era agradable con lo que sí quiero que sea a partir de ahora mi vida".

En esta obra está luchando por abrir un camino que le permite andar por un nuevo sendero y no volver siempre al mismo. Llama la atención que aunque la cúspide de la pirámide está truncada, (la cumbre es el final). Es interesante que ella no empieza el trabajo artístico o no lo centra en lo alto, (normalmente antes centraba su discurso en el pasado, y no focalizaba en el presente), ahora habla de trabajar la base de la pirámide. No se siente capaz de hacer un agujero tan grande para hacer un túnel, todavía no está preparada, pero es un agujero que simboliza la búsqueda de su salida, la salida que le permite vivir de una manera diferente sus problemas. La participante nombra su deseo de regenerar la base, y define la pirámide como una pirámide rota, que se rompió, pero que ella quiere reconstruir y para ello quiere empezar desde los cimientos de la misma.

\section{CONCLUSIONES}

En la primera etapa la participante mediante colores, formas y dibujos, ha ido desplegando y relacionado partes de las obras creadas con emociones como la angustia, la ansiedad, toda una serie de estados de malestar cuya causa desconocía. Estados de enfermedad no solo referida a la fibromialgia, si no trastorno conversivos, ingresos en urgencia por somatizaciones... En esta fase, la participante se ha servido 
del proceso creativo y de los materiales para poder ir sacando la agresividad, rabia, impotencia y odio acumulado entre otras emociones. El hecho de transferir emociones a un objeto creado, le ha posibilitado poder sacar de adentro hacia afuera y trabajar dichas emociones desde el afuera. El poder ver esas emociones mediante una obra concreta, definida, le ha permitido poder empezar a hablar de esas emociones que no podía ponerle nombre y poder empezar a identificar parte de su problemática. En la evaluación que ella hizo de su trabajo en esta primera etapa citó: "En las primeras obras eran todas muy sombrías, con poca alma, ni alegría, lo cual me ha hecho cambiar en muchos aspectos físicos y emocionales".

La segunda etapa, se produce cuando la participante de una manera simbólica y creativa, ha podido sacar su lado "negro, oscuro, de maldad" mediante la creación, y puede nombrarlo, reconocerlo, identificarlo y empezar a trabajar con ello. En esta etapa, la participante empieza a sentir que puede "ser ella misma". La estética de la obra se caracteriza ahora por una ausencia total del color negro y es representada con muchos colores. Asimismo, la participante experimenta una mejoría porque empieza a sentir un poco de discriminación y conocimiento a lo que le sucedía. En cierto modo, no está ya tanto a la merced de una angustia inconsciente. Paralelamente, se va estableciendo una relación entre malestar psíquico-trauma en la infancia-los mandatos de género-conversión en el cuerpo; o la hostilidad reprimida-autoagresiónsomatizaciones.

En la $3^{\circ}$ fase del taller, la participante puede ir comprendiendo más profundamente como su novela familiar ha sido determinante en la construcción que ha hecho sobre el amor, y sobre lo que espera de los otros. Pueden tomar conciencia de que el modo de relacionarse hacia los demás está marcado por la dependencia y condicionado por las necesidades que le causa mucho sufrimiento. Y puede ir ampliando otros modos de ver la realidad, no tan categórica, hierática, hasta el momento. Poder salir de esa percepción de "no me quieren", "no me entiende", "no me dan lo que yo necesito", le ha dado la posibilidad de comprender que la falta que vivía actualmente corresponde a eso que no tuvo en su infancia, pero que ya nadie puede suplirla excepto ella, y consecuentemente, le posibilitó empezar a reactualizar relaciones con su familia, concretamente con su hermana y su madre. Estaba en un estado de espera, en el cual, quería encontrar en esas figuras lo que no le fue dado en la infancia, y ello le conducía a una repetición marcada por la frustración, que le abocaba a un estado de somatización constante y de enfermedad. Poder comprender que ya nadie nos va a dar aquello y que solo nosotras podemos suplir, mediante el aprendizaje y la búsqueda de un "como" que promueva recursos y estrategias que nos permitan reconstruir nuestra imagen interna y reparar nuestra falta, fue lo que le posibilitó avanzar y salir de la repetición. Poco a poco en esta fase junto con la anterior, aprendió a acercarse a su madre y a su hermana no tanto desde la recriminación, la culpa, la espera de recibir, si 
no desde una relación donde ella podía hacerse cargo en mayor medida de sus emociones. RP citó:

"Me fue especialmente importante la propuesta de mostrar nuestros sueños, anhelos, emociones antes y los que queríamos tener, en lo que me sirvió, recordar lo que no quería y había sufrido por fuera y al abrir por dentro, encontrar lo que quiero y necesito, le puse el nombre de mi Caja de Pandora".

A través de los talleres ha podido actualizar los modelos internalizados, ha pasado de la relación que le hacía daño a una actualización de la misma, la cual, le ha permitido ver y relacionarse con su familia desde el presente y desde como son ellos. Y paralelamente, se disminuyó los trastornos conversivos y los ingresos a urgencias que le permitieron espacios para poder estar sola y pensar a sí misma, experimentando una sensación de "libertad".

En esta fase y en la anterior también se trabajó con los mandatos de género, se reflexionó sobre los roles asignados a la mujer y como cuando se salen de los mismos puede provocar conflictos, culpa, no aceptación, para poder comprender que a veces, las maneras de sentirnos no hablan tanto de nosotras mismas si no de como la sociedad ha impuesto que se tiene que ser y que esa imposición genera malestar en las mujeres. Se trabajó ese doble frente, los mandatos de género que tenía una relación en la autopercepción, estima de ellas mismas, y se trabajó también para poder poner de relieve la importancia de la reeducación de los valores impuestos que, como ellas contaban en su historia, les había hecho mucho daño.

En la cuarta etapa, se ahondó aún más en la problemática que giraba en torno a la dependencia, reconocimiento y obtención de amor por parte del Otro. Sobre los temas que se habían identificado como núcleos de dolor, se trabajó mediante el modelo de artistas que habían trabajado esas problemáticas a través del arte, y que habían podido reelaborar y reconstruir aspectos de su subjetividad mediante la creación.

Al final de los talleres, podía observarse otros cambios en relación al aspecto físico: había disminuido el hieratismo y el peso en la postura corporal y en el rostro; venía más feliz; había disminuido la dosis de la medicación de la depresión, así como hay mejorías en los resultados de los cuestionarios pasados al inicio de la intervención y al final, donde se analizan las dimensiones de: afrontamiento del dolor, calidad de vida, depresión, percepción del dolor. Y quizás un dato que puedo recoger como lo más ilustrativo a los cambios, es la cita que ella hace en el último taller sobre cómo se siente: tranquila, serena, en paz consigo misma, porque ha podido conocerse. Al paso de los meses tuvimos un encuentro para valorar cómo se encontraba, pudiéndose recoger en la entrevista semiestructurada que los cambios experimentados no habían variado. 


\section{BIBLIOGRAFÍA}

AMOROS, C. (1988): Mujeres, feminismo y poder, Forum de política feminista. Conferencia, Madrid.

BEAUVOIR, S. (2008): El segundo sexo, Cátedra, Madrid, 2008.

BEMJAMIN, J. (1996): Los lazos del amor, Buenos Aires, Paidós

BERROCAL, M. L. (2011): Tejiendo derechos, VII Jornadas sobre Violencia de Género y VIH. Mesa redonda: al hilo de las políticas sexual.

CASSIER, E. (1955): Mythical Thought, New Haven \& London, Yale University Press.

CIGARÁN, S. (2004): Danza Movimiento Terapia y Fibromialgia: una aproximación al dolor en todas sus dimensiones. Tesis Doctoral Universidad de Deusto, Facultad de Filosofía y Ciencias de la Educación. Bilbao.

CIGARÁN, S. (2011): "Moviéndonos más allá del diagnóstico, conclusiones tras 10 años de experiencia con la población de fibromialgia y dolor crónico". Revista LCS La sana crítica. Asociación Vasca de Fibromialgia y Astenia Crónica, $\mathrm{n}^{\circ} 19$.

CORIA, C. (2005): "Otra vida es posible en la edad media de la vida", en Coria, Clara, Freixas, Anna, y Covas, Susana. (2005). Los cambios en la vida de las mujeres: temores, mitos y estrategias, Barcelona, Ed. Paidós

SANZ, F. (1995): Los vínculos amorosos, Barcelona, Kairós.

FREUD, S. (1966): "The dynamics of the transference", J. Strachey The standard edition of the complete psychological works of Sigmund Freud (Vol. 12, pp. 99-108). London, Hogarth Press.

FREUD, S. (1915): "Observations on transference-love". Technique of psycho-analysis. S.E., 12:159-171.

INSTITUTO DE LA MUJER (2010): "Mujeres y salud". Revista de Comunicación Interactiva. Monográfico Salud Mental: el trasfondo del malestar, 29.

GONZÁLEZ DE CHAVEZ, A (2010): "Mujeres y salud". Revista de Comunicación Interactiva. Monográfico Salud Mental: el trasfondo del malestar, 29.

GUIOTE, A (2011): “Arteterapia y Fibromialgia, Lenguajes del Cuerpo". Revista de Arteterapia y educación para la inclusión social, 6. Universidad Complutense de Madrid.

GREESON R. R. (1967): The Technique and Practice of Psycho-Analysis, Vol 1. London, Hogarth, 1974.

LASHERAS, M. L., PIRES, M. y RODRÍGUEZ, M. (2004): Género y salud. Sevilla, Instituto Andaluz de la Mujer. Unidad de Igualdad y Género. Junta de Andalucía.

HERNANDO, A. (2000): La construcción de la subjetividad femenina. Madrid, Instituto de Investigaciones Feministas de la Universidad Complutense de Madrid

LEVINTON, N (2003): "Mujeres y deseo de poder: un conflicto inevitable". Dins ¿Desean las mujeres el poder? Madrid, Instituto de Investigaciones Feministas. Minerva Ediciones

LEVINTON, N. (2009): "Llegar a ser Simone de Beauvoir", Investigaciones feministas, 0. Universidad Complutense de Madrid, p.77-99. 
SEN, G, GEORGE, A. y OSTLIN, P. (2005): "Incorporar la perspectiva de género en la equidad en salud: un análisis de la investigación y las políticas". Organización Panamericana de la Salud.

OMENAT, M (2006): "Arteterapia con mujeres que han sufrido violencia de género: Valor y uso del objeto artístico". Revista Arteterapia. Dinámicas entre creación y procesos terapéuticos. Universidad de Murcia.

SCHAVERIAN, J. (1999): "Art within analysis: scapegoat, transference and transformation". Journal of Analytical Psychology, 44, P. 479-519.

TAVORA, A. (2003): "Ser feminista, ser psicoterapeuta". Cuadernos de Salud Pública,

TAVORA, A.(2005): “¿Por qué analizar el amor? Nuevas posibilidades para el estudio de las desigualdades de género". Comunicación presentada dentro del Simposio Cambios culturales y desigualdades de género en el marco local-global actual que tendrá lugar dentro del X Congreso de Antropología de la F.A.A.E.E., en Sevilla los días 19 al 22 de septiembre.

TAVORA, A. (2007): Centro de Profesorado y Recursos (CPR) de Avilés. Ricardo Solís http://www.Ine.es/aviles/1560/ideal-debe-mujer-afecta-salud/496412.html

TAVORA, A. (2008): "El amor romántico y la subordinación social de las mujeres: revisiones y propuesta". Anuario de psicología, 39. Nº . Facultad de Psicología. Universidad de Barcelona.

RIVIÉRE PICHON, E (1985): El concepto de portavoz, Buenos Aires, Temas de Psicología Social.

WINNICOTT, D (2002):Realidad y juego, Gedisa. 